\title{
Article \\ Population Pharmacokinetics of Piperacillin in Non-Critically Ill Patients with Bacteremia Caused by Enterobacteriaceae
}

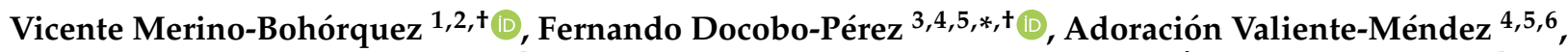 \\ Mercedes Delgado-Valverde ${ }^{4,5,6}$, Manuel Cameán ${ }^{1}$, William W. Hope ${ }^{7,8}$, Álvaro Pascual ${ }^{3,4,5,6}$ and \\ Jesús Rodríguez-Baño ${ }^{4,5,6,9}$
}

1 Unidad de Gestión de Farmacia Hospitalaria, Hospital Universitario Virgen Macarena, 41009 Sevilla, Spain; vicente.merino.sspa@juntadeandalucia.es (V.M.-B.); manuel.camean.sspa@juntadeandalucia.es (M.C.)

2 Departamento de Farmacología, Universidad de Sevilla, 41009 Sevilla, Spain

3 Departamento de Microbiología, Universidad de Sevilla, 41009 Sevilla, Spain; apascual@us.es

4 Instituto de Biomedicina de Sevilla IBIS, Hospital Universitario Virgen Macarena/CSIC/Universidad de Sevilla, 41013 Sevilla, Spain; adoracion.valiente.sspa@juntadeandalucia.es (A.V.-M.); mercdss@gmail.com (M.D.-V.); jesusrb@us.es (J.R.-B.)

5 Red Española de Investigación en Patología Infecciosa (REIPI RD16/0016), Instituto de Salud Carlos III, 28029 Madrid, Spain

6 Unidad Clínica de Enfermedades Infecciosas, Microbiología y Medicina Preventiva, Hospital Universitario Virgen Macarena, 41009 Sevilla, Spain

Citation: Merino-Bohórquez, V.; Docobo-Pérez, F.; Valiente-Méndez, A.; Delgado-Valverde, M.; Cameán, M.; Hope, W.W.; Pascual, Á.; Rodríguez-Baño, J. Population Pharmacokinetics of Piperacillin in Non-Critically Ill Patients with Bacteremia Caused by Enterobacteriaceae. Antibiotics 2021, 10, 348. https://doi.org/10.3390/ antibiotics 10040348

Academic Editor: Jeffrey Lipman

Received: 1 March 2021

Accepted: 23 March 2021

Published: 25 March 2021

Publisher's Note: MDPI stays neutral with regard to jurisdictional claims in published maps and institutional affiliations.

Copyright: (c) 2021 by the authors. Licensee MDPI, Basel, Switzerland. This article is an open access article distributed under the terms and conditions of the Creative Commons Attribution (CC BY) license (https:/ / creativecommons.org/licenses/by/ $4.0 /)$.
7 Department of Molecular and Clinical Pharmacology, University of Liverpool, Liverpool L69 3GE, UK; william.hope@liverpool.ac.uk

8 Royal Liverpool and Broadgreen University Hospital Trust, Liverpool L69 3GE, UK

9 Departamento de Medicina, Universidad de Sevilla, 41009 Sevilla, Spain

* Correspondence: fdocobo1@us.es

+ These authors contributed equally to this work.

\begin{abstract}
This study analyzes the pharmacokinetic variability of piperacillin in non-critically ill patients with Enterobacteriaceae bloodstream infections (EBSI) and explores predicted clinical outcomes and piperacillin-related neurotoxicity under different renal conditions. Hospitalized, non-critically ill patients treated with piperacillin-tazobactam for EBSI were included. Four serum samples per patient were collected and analyzed. A population pharmacokinetic model was developed using the Pmetrics package for R. Monte Carlo simulations of various dosage regimens of $4 \mathrm{~g}$ piperacillin, administered $\mathrm{q} 8 \mathrm{~h}$ or $\mathrm{q} 12 \mathrm{~h}$ by short $(0.5 \mathrm{~h})$ or long $(4 \mathrm{~h})$ infusion, following the different glomerular filtration rate (GFR) categories used to classify chronic kidney disease (Kidney Disease: Improving Global Outcomes, KDIGO) to determine the probability of target attainment (PTA) using a free drug concentrations above the minimal inhibitory concentration $(f \mathrm{~T}>\mathrm{MIC})$ of $50 \%$ for efficacy and targets for piperacillin-associated neurotoxicity. Twenty-seven patients (102 samples) were included. Extended piperacillin infusions reached a PTA > 90\% (50\% $f$ T $>$ MIC) within the susceptibility range, although a loading dose did not greatly improve the expected outcome. Long infusions reduced the expected toxicity in patients with severe renal impairment. The study supports the use of extended infusions of piperacillin in non-critically ill patients with EBSI. No benefits of a loading dose were expected in our population. Finally, extended infusions may reduce the risk of toxicity in patients with severe renal impairment.
\end{abstract}

Keywords: bloodstream infection; renal function; neurotoxicity; nephrotoxicity; pharmacokinetics; piperacillin-tazobactam; Enterobacteriaceae

\section{Introduction}

Enterobacteriaceae infections are associated with increased morbidity and mortality [1-3], which is mainly related to delay in providing active therapy, together with the lower efficacy of certain alternative drugs compared with first-line antibiotics. In this 
respect, appropriate initial antimicrobial therapy is of key importance for the resolution of serious infections. Several studies have demonstrated that inappropriate empiric therapy is independently associated with a worse outcome in patients with bacteremia caused by Enterobacteriaceae [1,4].

Piperacillin is a beta-lactam antibiotic, commonly combined with tazobactam, with a broad spectrum of bactericidal activity against Gram-negative and Gram-positive aerobes and anaerobes [5], and is frequently used for the empiric treatment of severe infections potentially caused by extended-spectrum beta-lactamase (ESBL)-producing Enterobacteriaceae and Pseudomonas aeruginosa [5]. Beta-lactam activity is related to the fraction of the dosing interval during which free drug concentrations remain above the minimal inhibitory concentration $(f \mathrm{~T}>\mathrm{MIC})$ for the relevant pathogen [6]. In the case of piperacillin, an $f \mathrm{~T}>\mathrm{MIC}$ of at least $50 \%$ of the dosing interval is considered necessary for maximal activity [7]. Most studies included in systematic reviews and meta-analyses across a wide range of severely ill patients admitted to intensive care units (ICU) found significant benefits in terms of mortality and clinical cure associated with prolonged versus intermittent infusions of piperacillin-tazobactam (TZP) [8,9]. Despite these obvious benefits, a survey on antimicrobial dosing in the ICU found wide variability in reported practices for TZP dosing and monitoring [10]. While there is an extensive published literature on piperacillin pharmacokinetics (PK) concerning variability in plasma concentrations and strategies aimed at optimizing efficacy in critically ill patients [11-13], there is scant information relating to non-critically ill patients. Piperacillin has been found to be safe and well tolerated in many clinical trials [14]. Even so, recent studies have shown neurological deterioration related to high piperacillin serum concentrations in a range from $11.4 \%$ to $43.3 \%$ and nephrotoxicity in $8.5 \%$ of non-ICU and ICU patients $[15,16]$. Two different papers have suggested pharmacokinetic targets associated with piperacillin-related neurotoxicity. Quinton et al. found that a serum concentration threshold of $157.2 \mathrm{mg} / \mathrm{L}$ is predictive of the occurrence of piperacillin neurotoxicity, [15] while Imani et al. found that a piperacillin $\mathrm{C}_{\min }>361.4 \mathrm{mg} / \mathrm{L}$ or $>452.65 \mathrm{mg} / \mathrm{L}$ was associated with a $50 \%$ risk of developing a neurotoxicity or nephrotoxicity event, respectively [16].

The aim of this prospective study was to describe the population PK of piperacillin in a cohort of non-critically ill patients with bloodstream infection (BSI) due to Enterobacteriaceae and to perform Monte Carlo simulations to explore the safety and expected outcomes of different dosing regimens suitable for non-critically ill patients.

\section{Results}

\subsection{Patients}

A total of 27 non-critically ill patients treated with piperacillin-tazobactam for Enterobacteriaceae BSI were included. Demographic, epidemiological, clinical, and microbiological variables and the outcomes of episodes are shown in Table 1 . Three patients with creatinine clearance $(\mathrm{CrCl})<20 \mathrm{~mL} / \mathrm{min} / 1.73 \mathrm{~m}^{2}$ received $4 / 0.5 \mathrm{~g}$ every $12 \mathrm{~h}$. A total of 102 plasma samples were collected at steady state during a single dosing interval. None of the determinations were below the limit of quantification. The most common source of bacteremia was the urinary tract $(66.7 \%)$. Escherichia coli and Klebsiella pneumoniae were the most frequently isolated microorganisms. The piperacillin-tazobactam MIC was $\leq 8 \mathrm{mg} / \mathrm{L}$ in 24 patients. One patient died (3.7\%), and no adverse events related to piperacillintazobactam administration were noted. 
Table 1. Baseline demographic and clinical characteristics of 27 patients with bloodstream infections due to Enterobacteriaceae, treated with piperacillin-tazobactam (TZP). Data are number of patients (percentage), unless otherwise stated. $\mathrm{CrCl}$, creatinine clearance, Sequential Organ Failure Assessment (SOFA), ESBL, extended-spectrum beta-lactamase, MIC,

\begin{tabular}{|c|c|}
\hline Variable & $\begin{array}{c}\text { No. of Cases (\%) } \\
\text { Unless Otherwise Stated }\end{array}$ \\
\hline Male gender & $17(62.96)$ \\
\hline Age in years, median (range) & $76.5(48-86)$ \\
\hline Body mass index $\geq 25$ & $19(79.1)$ \\
\hline $\mathrm{CrCl}$ in $\mathrm{mL} / \mathrm{min}$, median (range) & $50.7(45.3-255.3)$ \\
\hline Charlson score, median (range) & $2.5(0-8)$ \\
\hline Comorbidities: & \\
\hline Diabetes mellitus & $13(48.1)$ \\
\hline Chronic pulmonary disease & $4(14.8)$ \\
\hline Cancer & $11(40.7)$ \\
\hline Liver cirrhosis & $1(3.7)$ \\
\hline Immunosuppressive therapy & $1(3.7)$ \\
\hline \multicolumn{2}{|l|}{ Source of bacteremia } \\
\hline Urinary tract & $18(66.67)$ \\
\hline Biliary tract & $7(25.9)$ \\
\hline Other intraabdominal infection & $2(7.4)$ \\
\hline Community-acquired bacteremia & $11(40.7)$ \\
\hline Pitt score, median (range) & $2(0-5)$ \\
\hline SOFA score at diagnosis, median (range) & $3(0-8)$ \\
\hline \multicolumn{2}{|l|}{ Microorganism: } \\
\hline Escherichia coli & $15(55.5)$ \\
\hline Klebsiella oxytoca & $6(22.2)$ \\
\hline Klebsiella pneumoniae & $3(11.1)$ \\
\hline Enterobacter aerogenes & $2(7.4)$ \\
\hline Enterobacter cloacae & $1(3.7)$ \\
\hline \multicolumn{2}{|l|}{$\begin{array}{c}\text { ESBL producer } \\
\text { Hours from blood culture until first TZP }\end{array}$} \\
\hline Hours from blood culture until first TZP & $1.6(0-11)$ \\
\hline MIC & $25(92.5)$ \\
\hline $1 \mathrm{mg} / \mathrm{L}$ & $3(12)$ \\
\hline $2 \mathrm{mg} / \mathrm{L}$ & $13(52)$ \\
\hline $4 \mathrm{mg} / \mathrm{L}$ & $5(20)^{1}$ \\
\hline $8 \mathrm{mg} / \mathrm{L}$ & $3(12)^{2}$ \\
\hline $16 \mathrm{mg} / \mathrm{L}$ & 0 \\
\hline$>16 \mathrm{mg} / \mathrm{L}$ & $1(3.7)$ \\
\hline Outcome: & \\
\hline Lack of improvement, day 2 & $5(18.5)$ \\
\hline Clinical failure, day 14 & $4(14.8)$ \\
\hline Mortality, day 30 & $1(3.7)$ \\
\hline
\end{tabular}

${ }^{1} 2$ were ESBL producers. ${ }^{2} 1$ was an ESBL producer.

\subsection{Pharmacokinetic Model}

The piperacillin concentration-time data were best described by the one-compartment linear model, and no significant reduction in the log-likelihood value was observed compared with the two- or three-compartment models. The inclusion of creatinine clearance $(\mathrm{CrCl})$ as a covariate best described drug clearance $(\mathrm{CL})$ and reduced the log-likelihood value by 152 points. No other covariates improved the final model. The ordinary differential Equation (1) for the model is the following:

$$
d C / d t=R(1)-\left((\text { Intercept }+ \text { Slope } \times C l C r) / V_{c}\right) \times X_{1}
$$

$X_{1}$ is the amounts of piperacillin (in milligrams) in the central and peripheral compartment, respectively. Intercept and slope are the coefficients of a linear relationship of piperacillin clearance versus $\mathrm{ClCr}$. The final parameter estimates from the population model are presented in Table 2, and the observed-versus-individual predicted piperacillin concentrations appear in Figure 1. 
Table 2. Final population pharmacokinetic parameter estimates for 27 patients with bloodstream infections due to Enterobacteriaceae treated with piperacillin-tazobactam.

\begin{tabular}{cccc}
\hline Parameter & Mean & SD & Median \\
\hline $\begin{array}{c}\text { Drug Clearance, } \mathrm{CL}(\mathrm{L} / \mathrm{h}) \\
\mathrm{CL}=\text { Intercept }+ \text { slope } \times \text { creatinine clearance }(\mathrm{L} / \mathrm{h})\end{array}$ & & & \\
\hline Intercept $(\mathrm{L} / \mathrm{h})^{1}$ & 4.556 & 5.035 & 3.503 \\
\hline Slope & 1.353 & 1.032 & 1.39 \\
\hline Volume of distribution, $\mathrm{V}_{\mathrm{c}}(\mathrm{L})$ & 30.68 & 23.349 & 20.039 \\
\hline
\end{tabular}

${ }^{1}$ Intercept and slope are the coefficients of a linear relationship of piperacillin clearance versus $\mathrm{ClCr}$.
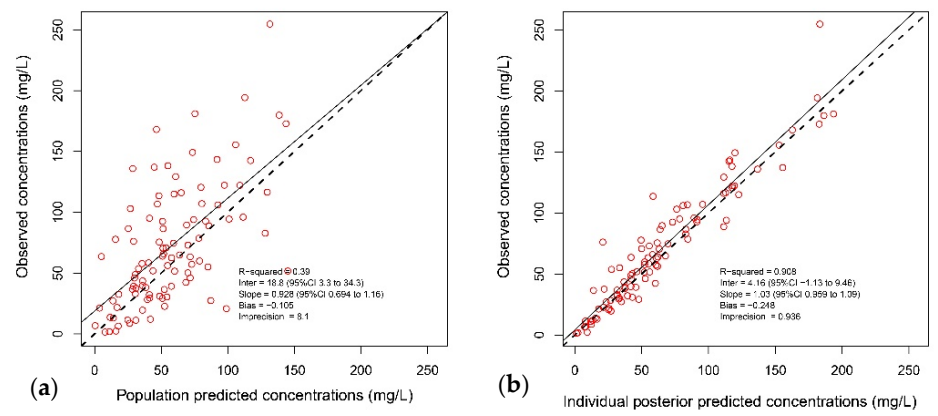

Figure 1. Diagnostic plots of the final population pharmacokinetic covariate model. (a) Observed piperacillin concentrations versus population predicted concentration $\left(R^{2}=0.39\right)$; $(b)$ observed piperacillin concentrations versus individual predicted concentrations $\left(R^{2}=0.908\right)$. The continuous line represents the regression line, and the dashed line is the line of identity.

The results of the normalized distribution prediction error (NPDE) analysis (Q-Q plot and histogram) are summarized graphically in Figure 2. The weighted residual error distributions are shown in Figure 3. The NPDEs ( $p=0.069$ in the Shapiro-Wilk test of normality), weighted residual error distributions, and visual predictive check (VPC) plot (Figure 2) suggest that the fit of the model to the data was acceptable.
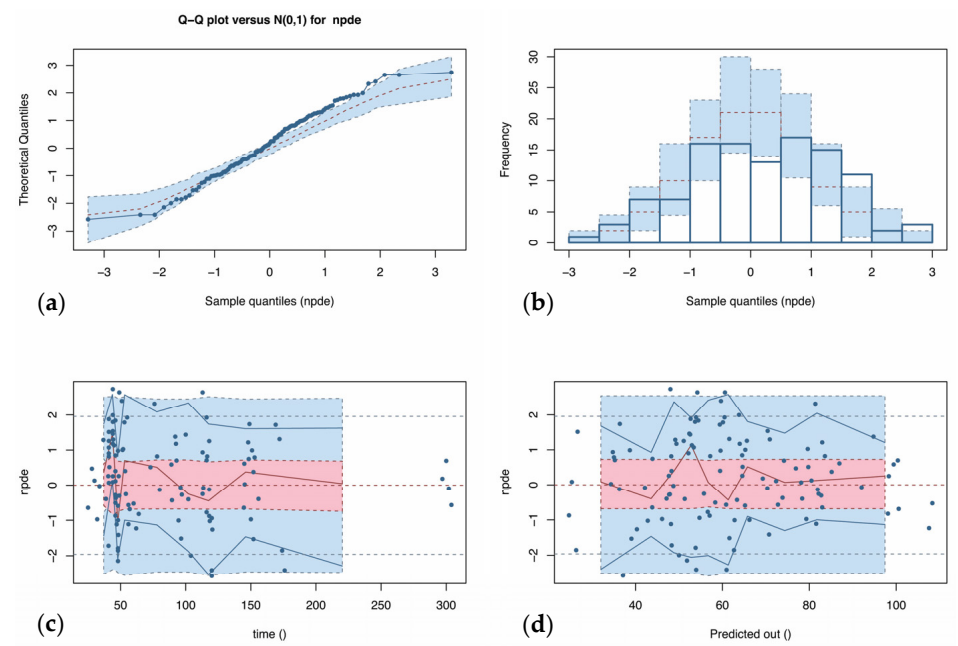

Figure 2. Normalized distribution predicted error (NPDE) versus predicted piperacillin concentration (a) and time (b). The NPDE should be a standard normal distribution with a mean of 0 and a standard deviation of 1, i.e., $\sim N(0,1)$. The approximately normal distribution of NPDE points, as indicated by the quantile-quantile (Q-Q) plot (c) and the NPDE histogram (d), centered at 0 , indicates that the population model predictions are minimally systematically biased. The horizontal dashed lines in the top left and top right panels are at $-2,0$ (the mean), and +2 standard deviations for the ideal normal distribution, and the surrounding error of $95 \%$ is shown with gray boxes. The solid horizontal lines are the actual distributions of the NPDE. The histogram columns in the bottom right panel compare the actual frequencies of NPDE with the ideal normal distribution (dashed line). 


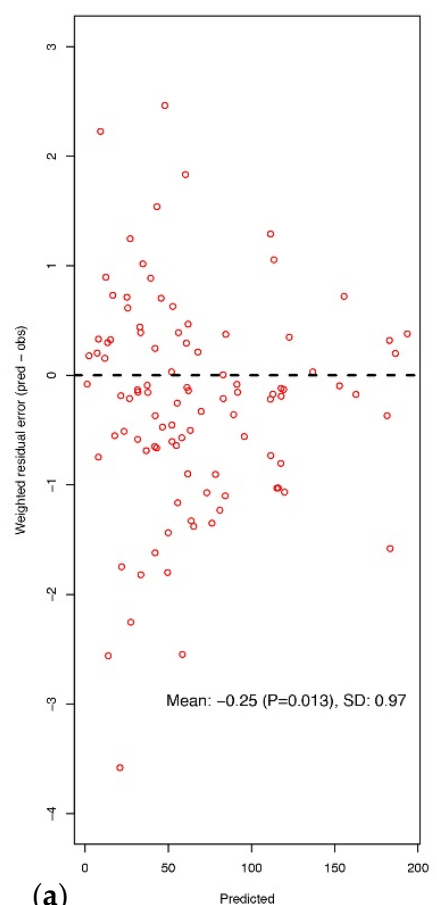

(a)

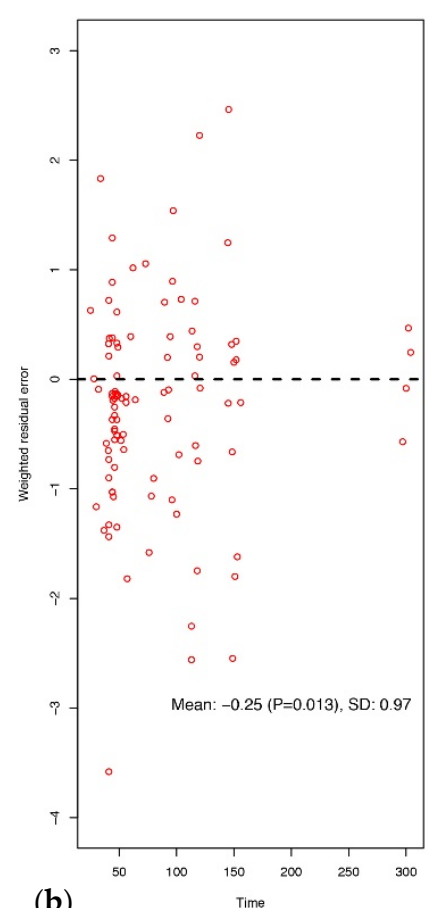

(b)

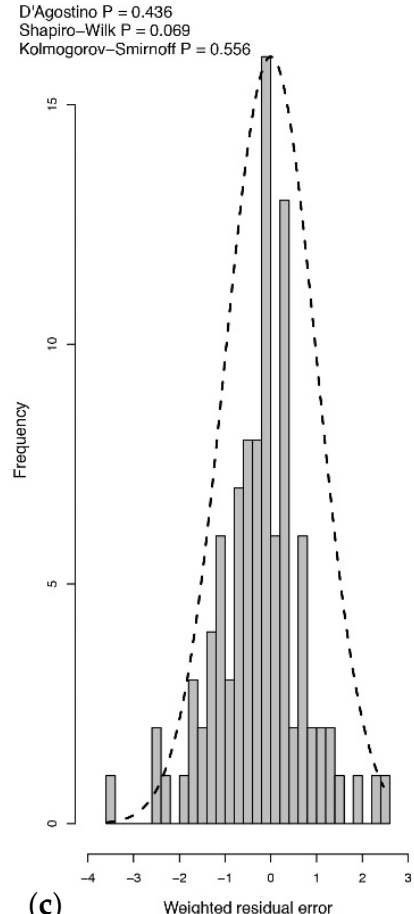

(c)

Figure 3. Weighted residual error plot (population predicted versus observed concentrations, $\mathrm{mg} / \mathrm{L}$ ) versus population predictions (a) and time of observation (b) and frequency distribution of weighted residual errors (c).

\subsection{Probability of Target Attainment}

The Monte Carlo simulations of varying piperacillin regimens and the probabilities of target attainment (PTAs) for $>50 \% f \mathrm{~T}>$ MIC are shown in Table 3. The results showed that the lower PTA ( $f \mathrm{~T}>\mathrm{MIC}$ for $50 \%$ of the dosing interval) was associated with a higher $\mathrm{ClCr}$. Piperacillin dosages of $4 / 0.5 \mathrm{~g}$ ( $4 \mathrm{~h}$ infusion) $\mathrm{q} 8 \mathrm{~h}$ or first dose [ $4 / 0.5 \mathrm{~g}(0.5 \mathrm{~h}$ infusion $)+4 \mathrm{~g}$ ( $4 \mathrm{~h}$ infusion)] followed by $4 / 0.5 \mathrm{~g}$ ( $4 \mathrm{~h}$ infusion) $\mathrm{q} 8 \mathrm{~h}$ reached a PTA of $>90 \%$ within the current breakpoint (i.e., piperacillin MIC $\leq 8 \mathrm{mg} / \mathrm{L}$ ). In this analysis, no significant benefit of a loading dose was observed. An extended infusion, alone or given with a loading dose, showed slightly a better PTA than the short piperacillin infusion.

Table 3 also shows the PTAs for $>50 \% f \mathrm{~T}>$ MIC with different dosage regimen adjustments and levels of creatinine clearance. With a dosage adjustment of $4 / 0.5 \mathrm{~g}$ ( $0.5 \mathrm{~h}$ infusion) $\mathrm{q} 12 \mathrm{~h}$, patients with severely reduced renal function or kidney failure achieved the optimal targets of $f \mathrm{~T}>\mathrm{MIC}>50 \%$ over the dosing interval within the susceptible range. A prolonged infusion administration $(4 \mathrm{~h})$ improved the PTA within the intermediate category compared with a short one, and similar results were found with the addition of a loading dose. 
Table 3. Probability of target attainment (PTA) using an $f \mathrm{TMIC}_{0-24 \mathrm{~h}}=50 \%$ as pharmacodynamic target after simulation in patients with normal or severe renal impairment according to KDIGO clinical practice guideline for acute kidney injury: Dosage 1, $4 \mathrm{~g}$ (0.5 h infusion) q8 h; Dosage 2, $4 \mathrm{~g}$ (4 h infusion) $\mathrm{q} 8 \mathrm{~h}$; Dosage 3, first dose [4 $\mathrm{g}$ (0.5 h infusion) $+4 \mathrm{~g}$ (4 h infusion)] followed by $4 \mathrm{~g}$ (4 h infusion) q8 h. Dosage 4, $4 \mathrm{~g}$ (0.5 h infusion) q12 h; Dosage 5, $4 \mathrm{~g}$ ( $4 \mathrm{~h}$ infusion) q12 h; Dosage 6, first dose [ $4 \mathrm{~g}(0.5 \mathrm{~h}$ infusion $)+4 \mathrm{~g}$ ( $4 \mathrm{~h}$ infusion)] followed by $4 \mathrm{~g}$ ( $4 \mathrm{~h}$ infusion) $\mathrm{q} 12 \mathrm{~h}$. Green, yellow, and red boxes indicate piperacillin PTA $\geq 90 \%,<90-\geq 50 \%$, and $<50 \%$, respectively.

\begin{tabular}{|c|c|c|c|c|c|c|}
\hline \multirow{3}{*}{$\begin{array}{c}\text { Target } \\
f \mathrm{~T}>\mathrm{MIC}=50 \% \\
\mathrm{MIC}(\mathrm{mg} / \mathrm{L})\end{array}$} & \multirow{2}{*}{\multicolumn{3}{|c|}{$\begin{array}{c}\text { Normal } \\
\left(90-129 \mathrm{~mL} / \mathrm{min} / 1.73 \mathrm{~m}^{2}\right)\end{array}$}} & \multicolumn{3}{|c|}{$\begin{array}{c}\text { Severely Decreased } \\
\left(15-29 \mathrm{~mL} / \mathrm{min} / 1.73 \mathrm{~m}^{2}\right) \\
\text { Kidney Failure } \\
\left(<15 \mathrm{~mL} / \mathrm{min} / 1.73 \mathrm{~m}^{2}\right)\end{array}$} \\
\hline & & & & & Dosag & \\
\hline & 1 & 2 & 3 & 4 & 5 & 6 \\
\hline 0.06 & 99.8 & 100 & 100 & 99.4 & 99.9 & 100 \\
\hline 0.125 & 99.2 & 100 & 100 & 99.2 & 99.9 & 100 \\
\hline 0.25 & 99 & 100 & 100 & 99.2 & 99.9 & 100 \\
\hline 0.5 & 98.8 & 100 & 100 & 99.2 & 99.8 & 100 \\
\hline 1 & 98.4 & 100 & 100 & 98.9 & 99.7 & 100 \\
\hline 2 & 97.4 & 100 & 100 & 98.8 & 99.6 & 100 \\
\hline 4 & 93.4 & 100 & 100 & 98.5 & 99.5 & 99.9 \\
\hline $\begin{array}{c}8 \\
\text { EUCAST (S) }\end{array}$ & 76.4 & 100 & 100 & 92.9 & 96.1 & 99.7 \\
\hline $\begin{array}{c}16 \\
\text { EUCAST (I) }\end{array}$ & 56.8 & 95.8 & 94.6 & 77.3 & 90.7 & 94.3 \\
\hline $\begin{array}{c}32 \\
\text { (EUCAST R) }\end{array}$ & 14.2 & 28 & 45.8 & 38.7 & 61.1 & 81.3 \\
\hline 64 & 1.2 & 2 & 8.4 & 6.9 & 11.7 & 31.8 \\
\hline 128 & 0 & 0 & 0.2 & 1.2 & 1.2 & 4.6 \\
\hline 256 & 0 & 0 & 0 & 0.2 & 0.2 & 0.7 \\
\hline
\end{tabular}

\subsection{Piperacillin Neurotoxicity and Nephrotoxicity}

At the simulated doses of $4 / 0.5 \mathrm{~g}$ ( $4 \mathrm{~h}$ infusion) $\mathrm{q} 8 \mathrm{~h}$ or first dose $[4 / 0.5 \mathrm{~g}(0.5 \mathrm{~h}$ infusion) $+4 \mathrm{~g}$ ( $4 \mathrm{~h}$ infusion)] followed by $4 / 0.5 \mathrm{~g}$ ( $4 \mathrm{~h}$ infusion) $\mathrm{q} 8 \mathrm{~h}$ in patients with normal renal function, no neurotoxicity or nephrotoxicity events were expected. With respect to the case with dose adjustments of piperacillin due to renal disease, the simulated patients did not reach the nephrotoxicity breakpoint of $\mathrm{C}_{\min }>452.65 \mathrm{mg} / \mathrm{L}$. Also, in these simulated group patients with severely decreased renal clearance or kidney failure, no neurotoxicity in those who received short-term intravenous infusions was predicted. However, long infusions or the addition of a loading dose slightly increased the risk of expected neurotoxicity to $0.2 \%$ and $0.3 \%$, respectively (targeting at $C_{\min }>157.2 \mathrm{mg} / \mathrm{L}$ ).

\section{Discussion}

The present study describes the population pharmacokinetics of piperacillin targeted at non-critically ill patients. We focused on PTA ( $50 \% f \mathrm{~T}>\mathrm{MIC})$ based on some traditional animal and human studies, although more demanding targets are used for critical patients, as the patients in our study were not critically ill [17-19]. We observed that only creatinine clearance significantly affected the pharmacokinetics of piperacillin. We also observed that an extended infusion of piperacillin improved the PTA ( $50 \% f \mathrm{~T}>\mathrm{MIC})$. Our data show that the currently suggested dosing regimen (4/0.5 g infusion over $30 \mathrm{~min} \mathrm{q} 8 \mathrm{~h}$ ) is less likely to attain the pharmacodynamic target in patients with normal or severe renal impairment. Other investigators have previously reported similar results in both critically and non-critically ill patients [20-22].

The administration of piperacillin by extended infusion, over half the dosing interval (i.e., infused over $4 \mathrm{~h}$, administered $\mathrm{q} 8 \mathrm{~h}$ ), or after an initial loading dose helped overcome subtherapeutic piperacillin drug exposures in all the simulated scenarios. This has previ- 
ously been shown in observational studies as well as randomized controlled trials (RCT) and also correlates with the higher rates of clinical cure in the RCTs [23-25]. In our model, we observed a slight benefit with the administration of a loading dose, especially against a piperacillin MIC of $32 \mathrm{mg} / \mathrm{L}$ (considered as resistant). We cannot rule out the possibility of an extended benefit in patients with augmented renal clearance $\left(>130 \mathrm{~mL} / \mathrm{min} / 1.73 \mathrm{~m}^{2}\right)$ or in patients with other baseline characteristics. These results differ somewhat with those of Rhodes et al. [26], who suggested that loading dosages may be necessary for their modeled dosing schedules of piperacillin-tazobactam by prolonged infusion ( $3.375 \mathrm{~g}$ infused over $4 \mathrm{~h}$ ) and continuous infusion (10.125 g infused over $24 \mathrm{~h}$ ) and for elevated MICs. However, in that study, the authors only analyzed the probability of and time to first instance of concentrations exceeding the breakpoint MIC for piperacillin-tazobactam $(16 \mathrm{mg} / \mathrm{L}$, Clinical and Laboratory Standard Institute [CLSI] breakpoints) over the first 120 min of therapy. It is also important to note that a different TZP dosage was used ( $3 \mathrm{~g}$ piperacillin plus $0.375 \mathrm{~g}$ tazobactam instead of $4 \mathrm{~g}$ piperacillin plus $0.5 \mathrm{~g}$ tazobactam).

Piperacillin-associated neurotoxicity in patients with dose adjustments due to impaired glomerular filtration rates was also analyzed. Piperacillin-associated neurotoxicity was not observed in our patients in this study, and simulations of extended infusions showed a probability of $<1 \%$ (targeting $C_{\min }>361 \mathrm{mg} / \mathrm{L}$ ), which contrasts with the probability of $11.4 \%$ observed by Imani et al. [16]. However, in the latter study, piperacillin dosages of 8-16 g/ $24 \mathrm{~h}$ at $6-12 \mathrm{~h}$ intervals were included. No information regarding dosage adjustment in patients with renal impairment was given, and this could explain the higher frequency found if piperacillin concentrations were not correctly adjusted. On the other hand, Quinton et al. analyzed a retrospective cohort of ICU patients [15], which showed a piperacillin-associated neurotoxicity of $43.4 \%$, using a piperacillin concentration equal to or higher than $157.2 \mathrm{mg} / \mathrm{L}$ as a target. Applying this breakpoint to our study, overall, we predict no neurotoxicity events in patients with normal renal function and a probability of $0.2-0.3 \%$ in those with adjusted doses (dosage $5,4 \mathrm{~g}$ ( $4 \mathrm{~h}$ infusion) $\mathrm{q} 12 \mathrm{~h}$ and dosage 6 , loading dose of $4 \mathrm{~g}$ ( $0.5 \mathrm{~h}$ infusion $)+4 \mathrm{~g}$ ( $4 \mathrm{~h}$ infusion) followed by $4 \mathrm{~g}$ ( $4 \mathrm{~h}$ infusion) $\mathrm{q} 12 \mathrm{~h}$ ) due to severe renal impairment. Nevertheless, the study by Quinton et al. was not intended to estimate the proportion of piperacillin-associated neurotoxicity, and such a frequency would probably be overestimated.

With regard to the absence of piperacillin-related nephrotoxicity observed in our patients with normal renal function or impaired renal function with adjusted dose, our results fit with our predicted nephrotoxicity event based on the target of $C_{\min }>452.65 \mathrm{mg} / \mathrm{L}$ [16]. However, Imani et al. showed nephrotoxicity events in $8.5 \%$ of the study population following exclusion criteria, which is higher than that observed in our patients. In this study, the use of a diuretic agent was associated with a significantly increased risk of piperacillin nephrotoxicity (OR 31.32, IC95\% 3.33-294.70, $p<0.01$ ). Apart from other baseline patient characteristics between both studies, the administration of this diuretic agent consumption was not taken into account in Imani's study. Thus, we cannot compare this important factor associated with nephrotoxicity with our population.

Although our findings highlight the importance of optimal dosing and administration of piperacillin based on renal clearance in non-critically ill patients in order to overcome subtherapeutic concentrations, only 27 patients were included in the present study, which limits the generalizability of these results. Additionally, the model was largely constructed using patients with normal renal function and few with severe renal impairment, which could impair the extrapolation of results to patients with extreme renal impairment. The $\mathrm{PK} / \mathrm{PD}$ target for predicting piperacillin efficacy also remains unclear. While the majority of centers currently performing $\beta$-lactam therapeutic drug monitoring (TDM) target values of $100 \% f \mathrm{~T}>\mathrm{MIC}$, others use $100 \% f \mathrm{~T}>4 \times \mathrm{MIC}, 50 \% f \mathrm{~T}>4 \times \mathrm{MIC}$, or $70 \% f \mathrm{~T}>4 \times$ MIC for certain $\beta$-lactams. Whether serum concentrations of $\beta$-lactams always need to be above the MIC requires prospective clinical validation [27]. Finally, because of the major differences in the expected piperacillin-associated neurotoxicity and nephrotoxicity based 
on the choice of published pharmacokinetic targets, the results should be interpreted with caution until they have been prospectively validated.

\section{Materials and Methods}

\subsection{Study Design and Patients}

A prospective study was conducted at the Hospital Universitario Virgen Macarena (Seville, Spain) between October 2012 and February 2015, including adult patients (age > 17 years) with BSI caused by Enterobacteriaceae who received initial monotherapy with piperacillintazobactam. Eligible patients were first identified from daily reports of blood cultures from the microbiology laboratory. Patients were included only if: the first piperacillintazobactam dose was administered in the first $12 \mathrm{~h}$ after collection of blood cultures, the duration of the therapy was at least $48 \mathrm{~h}$, and the patient was not admitted to the intensive care unit. Patients with any of the following criteria were excluded: transient bacteremia, polymicrobial bacteremia, non-hospitalized patients, patients with do-not-resuscitate orders, and neutropenic patients (absolute neutrophil count $<500 / \mathrm{mm}^{3}$ ). Written informed consent was obtained from all participants. The study was approved by the Ethics Committee of the Hospital Universitario Virgen Macarena (reference number 1578).

Demographic data (including the age, sex, height, and weight of the patient), mode of acquisition of the infection (nosocomial or community-acquired), source of BSI according to clinical and microbiological criteria, serum creatinine concentrations, adverse events potentially related to therapy and 30-day mortality were recorded. Collection of serum creatinine concentrations was standard-of-care, and creatinine clearance was calculated daily using the Cockcroft-Gault equation [28]. Glomerular filtration rate (GFR) was estimated using the Chronic Kidney Disease Epidemiology Collaboration (CKD-EPI) equation [29], the patients were classified according to the different GFR categories used to classify chronic kidney disease (KDIGO) [30]. Bacterial blood isolates were identified by MALDI-TOF, and piperacillin-tazobactam susceptibility testing was performed by the broth microdilution method, following the European Committee on Antimicrobial Susceptibility Testing (EUCAST) methodology. EUCAST breakpoints for piperacillin-tazobactam were used to interpret susceptibility [31].

\subsection{Antibiotic Therapy}

As local dosing recommendations changed in the course of the study period, patients received two different piperacillin-tazobactam regimens: (a) $4 / 0.5 \mathrm{~g}$ ( $4 \mathrm{~h}$ infusion) $\mathrm{q} 8 \mathrm{~h}$, and (b) first dose $4 / 0.5 \mathrm{~g}$ (30 min infusion) followed by $4 / 0.5 \mathrm{~g}$ ( $4 \mathrm{~h}$ infusion) starting immediately after the first dose and then $4 / 0.5 \mathrm{~g}$ ( $4 \mathrm{~h}$ infusion) $\mathrm{q} 8 \mathrm{~h}$, following Roberts et al. with modifications [12]. Patients with creatinine clearance $<20 \mathrm{~mL} / \mathrm{min} / 1.73 \mathrm{~m}^{2}$ (classified as severely decreased renal clearance or kidney failure) received $4 / 0.5 \mathrm{~g}$ every $12 \mathrm{~h}$, according to the summary of product characteristics (SPC) recommendations [32].

\subsection{Piperacillin Serum Concentration Assay}

Blood samples were taken at steady state, and sampling was performed 1, 4, 6, and $8 \mathrm{~h}$ after the commencement of piperacillin infusion, collected in EDTA tubes, centrifuged and stored at $-80^{\circ} \mathrm{C}$ until analysis. A high-performance liquid chromatography (HPLC) method described by McWhinney et al. was used to analyze piperacillin serum concentrations [33]. FDA guidance on bioanalytical method validation was used to validate the method [34]. The linear range of quantification was $1-500 \mathrm{mg} / \mathrm{L}$. Relative standard deviations and relative errors of the inter- and intra-assay were less than $8.2 \%$, and the lower limit of quantification was $1 \mathrm{mg} / \mathrm{L}$.

\subsection{Pharmacokinetic Analyses}

The nonparametric adaptive grid (NPAG) algorithm embedded in the Pmetrics software package was used to fit a population pharmacokinetic model to the data [35]. For the population pharmacokinetic analysis, one- and two-compartment linear models were 
fitted to the piperacillin plasma concentration-time data. Covariate model building was performed using sequential assessment of biologically plausible clinical parameters. Forward inclusion was based on the model selection criteria and significant correlation with one of the pharmacokinetic parameters. Creatinine clearance, weight, age, sex, and body mass index (BMI) were explored as covariates for each structural model. The data were weighted by the inverse of the estimated assay variance, which was determined from quality control samples used to estimate inter-day assay variance and given by $\mathrm{SD}(\mathrm{mg} / \mathrm{L})=$ gamma $\times(0.4388+0.027 \times \mathrm{C})$, where $\mathrm{C}$ is the piperacillin concentration, and gamma is an estimate of process noise expressed as multiples of assay variance [35]. The goodness-of-fit of each model to the data was assessed using a combination of the following: (i) log-likelihood values; (ii) coefficients of determination (R2) from linear regression of the observed vs. predicted values before and after the Bayesian step; (iii) minimization of bias and imprecision of the observed vs. predicted plots, (iv) normalized prediction distribution errors (NPDE); (v) the distribution of weighted residual errors; and (vi) a visual predictive check (VPC) plot.

\subsection{Simulations and Probability of Target Attainment}

A 2000-patient Monte Carlo simulation was performed using a semi-parametric sampling method available in Pmetrics [35,36]. The final model consisted of 13 support points. Each point was a set of values for each parameter in the model and the probabilities of those values to predict piperacillin concentrations observed in the population. Each support point then served as the mean for a multivariate normal distribution, weighted by the probability of the point, with covariance equal to the covariance matrix of the full model divided by the number of points (i.e., 13). Semi-parametric sampling from this weighted, multivariate, multimodal normal distribution was used to generate a simulated population of 2000 patients each with their own set of PK parameters. Piperacillin dosages, including short and extended infusions and a loading dose, were simulated as follows: Dosage 1, 4/0.5 g (0.5 h infusion) q8 h; Dosage 2, 4/0.5 g (4 h infusion) q8 h; Dosage 3, first dose $4 / 0.5 \mathrm{~g}$ ( $0.5 \mathrm{~h}$ infusion) followed by $4 / 0.5 \mathrm{~g}$ ( $4 \mathrm{~h}$ infusion) starting immediately after the first dose and then $4 / 0.5 \mathrm{~g}$ ( $4 \mathrm{~h}$ infusion) $\mathrm{q} 8 \mathrm{~h}$. Dose adjustments of piperacillin in patients with severely decreased renal clearance $\left(15-29 \mathrm{~mL} / \mathrm{min} / 1.73 \mathrm{~m}^{2}\right)$ and kidney failure $\left(<15 \mathrm{~mL} / \mathrm{min} / 1.73 \mathrm{~m}^{2}\right)$ were simulated with the aim of optimizing piperacillin pharmacodynamics in these patient subgroups. The following piperacillin dosages, which included standard short $(0.5 \mathrm{~h})$ and extended $(4 \mathrm{~h})$ infusion, were simulated: Dosage 1 , 4/0.5 g (0.5 h infusion) q12 h; Dosage 2, 4/0.5 g (4 h infusion) q12 h; Dosage 3, first dose [4/0.5 $\mathrm{g}(0.5 \mathrm{~h}$ infusion $)+4 / 0.5 \mathrm{~g}$ ( $4 \mathrm{~h}$ infusion)] followed by $4 \mathrm{~g}(4 \mathrm{~h}$ infusion) $\mathrm{q} 12 \mathrm{~h}$. For the probability of pharmacodynamic target attainment (PTA) analysis, MICs ranging between 0.0625 and $256 \mathrm{mg} / \mathrm{L}$ were assessed in doubling dilutions, using EUCAST susceptibility breakpoints (susceptible $\leq 8 \mathrm{mg} / \mathrm{L}$ and resistant $>16 \mathrm{mg} / \mathrm{L}$ ), and a pharmacodynamic index to predict efficacy, $f \mathrm{~T}_{\text {MIC }} \geq 50 \%$ of the dosing interval, was used [37]. The unbound fraction of piperacillin was fixed at 0.7 [38]. A PTA of $\geq 90 \%$ was considered optimal.

\subsection{Toxicodynamic Analysis}

The probability of reaching neurotoxicity- $\left(\mathrm{C}_{\min }\right.$ piperacillin steady-state concentrations above $361.4 \mathrm{mg} / \mathrm{L}$ or $157.2 \mathrm{mg} / \mathrm{L})$ and nephrotoxicity- $\left(\mathrm{C}_{\min }\right.$ piperacillin steady-state concentrations above $452.65 \mathrm{mg} / \mathrm{L}$ ) related thresholds, respectively, was analyzed over a $24 \mathrm{~h}$ interval (day 2) $[15,16]$. For these analyses, the unbound piperacillin concentration was used.

\section{Conclusions}

In conclusion, given the association between early and appropriate antibiotic therapy and improved clinical outcomes for critically ill patients $[1,4,39,40]$, our data support the use of extended piperacillin infusions early in patients with invasive infections caused by Enterobacteriaceae, even if the patients are not critically ill and have a low risk of 
neurotoxicity or nephrotoxicity events. The benefits of a loading dose are not clear and should be explored in other populations such as patients with augmented renal clearance. These findings should be confirmed in other studies with similar populations and by using clinical endpoints.

Author Contributions: Conceptualization, V.M.-B., F.D.-P. and J.R.-B.; methodology, V.M.-B., F.D.-P. and J.R.-B.; software, F.D.-P. and W.W.H.; validation, V.M.-B., F.D.-P. and J.R.-B.; formal analysis, V.M.B. and F.D.-P.; investigation, V.M.-B. and F.D.-P.; data curation, M.D.-V. and A.V.-M.; writing-original draft preparation, V.M.-B. and F.D.-P.; writing-review and editing, V.M.-B., F.D.-P., W.W.H., Á.P. and J.R.-B.; visualization, V.M.-B. and F.D.-P.; supervision, J.R.-B., Á.P. and M.C.; project administration, J.R.-B.; funding acquisition, J.R.-B. All authors have read and agreed to the published version of the manuscript.

Funding: This study was funded by Plan Nacional de I+D+i 2013-2016, Instituto de Salud Carlos III, Subdirección General de Redes y Centros de Investigación Cooperativa, Ministerio de Economía, Industria y Competitividad, Spanish Network for Research in Infectious Diseases (REIPI RD16/0016/0001) and PI10/02021, cofunded by European Development Regional Fund "A way to achieve Europe", Operative Programme Intelligent Growth 2014-2020.

Institutional Review Board Statement: The study was conducted according to the guidelines of the Declaration of Helsinki, and approved by the Ethics Committee of the University Hospital Virgen Macarena (protocol code 1578, date of approval 11 February 2013).

Informed Consent Statement: Informed consent was obtained from all subjects involved in the study.

Data Availability Statement: The data presented in this study are available on request from the corresponding author.

Acknowledgments: A.V.-M. is supported by a Rio Hortega fellowship from the Instituto de Salud Carlos III, Ministerio de Economía y Competitividad, and was the recipient of a grant from the Andalusian Society of Infectious Diseases (SAEI).

Conflicts of Interest: J.R.-B. has been scientific coordinator of a research project unrelated to the project funded by AstraZeneca and a speaker at accredited educational activities funded by Merck through unrestricted grants. J.R.-B. and A.P. received funding for research from COMBACTE-NET (grant agreement 115523), COMBACTE-CARE (grant agreement 115620), and COMBACTE-MAGNET (grant agreement 115737) projects under the Innovative Medicines Initiative (IMI), the European Union and EFPIA companies in kind. W.W.H. has received research funding from Pfizer, Gilead, Astellas, AiCuris, Amplyx, Spero Therapeutics, and F2G and has acted as a consultant and/or has given talks for Pfizer, Basilea, Astellas, F2G, Nordic Pharma, Medicines Company, Amplyx, Mayne Pharma, Spero Therapeutics, Auspherix, Cardeas, and Pulmocide. All other authors have no conflicts to declare.

\section{References}

1. Rodríguez-Baño, J.; Picón, E.; Gijón, P.; Hernández, J.R.; Ruíz, M.; Peña, C.; Almela, M.; Almirante, B.; Grill, F.; Colomina, J.; et al. Community-onset bacteremia due to extended-spectrum beta-lactamase-producing Escherichia coli: Risk factors and prognosis. Clin. Infect. Dis. 2010, 50, 40-48. [CrossRef]

2. Rodríguez-Baño, J.; Pascual, A. Clinical significance of extended-spectrum $\beta$-lactamases. Expert Rev. Anti. Infect. Ther. 2008, 6, 671-683. [CrossRef]

3. Rottier, W.C.; Ammerlaan, H.S.M.; Bonten, M.J.M. Effects of confounders and intermediates on the association of bacteraemia caused by extended-spectrum -lactamase-producing Enterobacteriaceae and patient outcome: A meta-analysis. J. Antimicrob. Chemother. 2012, 67, 1311-1320. [CrossRef] [PubMed]

4. Retamar, P.; Portillo, M.M.; López-Prieto, M.D.; Rodríguez-López, F.; de Cueto, M.; García, M.V.; Gómez, M.J.; Del Arco, A.; Muñoz, A.; Sánchez-Porto, A.; et al. Impact of inadequate empirical therapy on the mortality of patients with bloodstream infections: A propensity score-based analysis. Antimicrob. Agents Chemother. 2012, 56, 472-478. [CrossRef] [PubMed]

5. Gin, A.; Dilay, L.; Karlowsky, J.A.; Walkty, A.; Rubinstein, E.; Zhanel, G.G. Piperacillin-tazobactam: A beta-lactam/beta-lactamase inhibitor combination. Expert Rev. Anti. Infect. Ther. 2007, 5, 365-383. [CrossRef]

6. Craig, W.A. Basic pharmacodynamics of antibacterials with clinical applications to the use of beta-lactams, glycopeptides, and linezolid. Infect. Dis. Clin. N. Am. 2003, 17, 479-501. [CrossRef]

7. Kim, M.K.; Xuan, D.; Quintiliani, R.; Nightingale, C.H.; Nicolau, D.P. Pharmacokinetic and pharmacodynamic profile of high dose extended interval piperacillin-tazobactam. J. Antimicrob. Chemother. 2001, 48, 259-267. [CrossRef] 
8. Rhodes, N.J.; Liu, J.; O’Donnell, J.N.; Dulhunty, J.M.; Abdul-Aziz, M.H.; Berko, P.Y.; Nadler, B.; Lipman, J.; Roberts, J.A. Prolonged Infusion Piperacillin-Tazobactam Decreases Mortality and Improves Outcomes in Severely Ill Patients: Results of a Systematic Review and Meta-Analysis. Crit. Care Med. 2018, 46, 236-243. [CrossRef]

9. Falagas, M.E.; Tansarli, G.S.; Ikawa, K.; Vardakas, K.Z. Clinical outcomes with extended or continuous versus short-term intravenous infusion of carbapenems and piperacillin/tazobactam: A systematic review and meta-analysis. Clin. Infect. Dis. 2013, $56,272-282$.

10. Tabah, A.; De Waele, J.; Lipman, J.; Zahar, J.R.; Cotta, M.O.; Barton, G.; Timsit, J.-F.; Roberts, J.A. The ADMIN-ICU survey: A survey on antimicrobial dosing and monitoring in ICUs. J. Antimicrob. Chemother. 2015, 70, 2671-2677. [CrossRef]

11. Udy, A.A.; Lipman, J.; Jarrett, P.; Klein, K.; Wallis, S.C.; Patel, K.; Kirkpatrick, C.M.J.; Kruger, P.S.; Paterson, D.L.; Roberts, M.S.; et al. Are standard doses of piperacillin sufficient for critically ill patients with augmented creatinine clearance? Crit. Care 2015, 19, 28. [CrossRef] [PubMed]

12. Roberts, J.A.; Kirkpatrick, C.M.J.; Roberts, M.S.; Dalley, A.J.; Lipman, J. First-dose and steady-state population pharmacokinetics and pharmacodynamics of piperacillin by continuous or intermittent dosing in critically ill patients with sepsis. Int. J. Antimicrob. Agents 2010, 35, 156-163. [CrossRef] [PubMed]

13. Alobaid, A.S.; Wallis, S.C.; Jarrett, P.; Starr, T.; Stuart, J.; Lassig-Smith, M.; Mejia, J.L.O.; Roberts, M.S.; Roger, C.; Udy, A.A.; et al. Population Pharmacokinetics of Piperacillin in Nonobese, Obese, and Morbidly Obese Critically Ill Patients. Antimicrob. Agents Chemother. 2017, 61, e01276-16. [CrossRef]

14. Kuye, O.; Teal, J.; DeVries, V.G.; Morrow, C.A.; Tally, F.P. Safety profile of piperacillin/tazobactam in phase I and III clinical studies. J. Antimicrob. Chemother. 1993, 31 (Suppl. A), 113-124. [CrossRef]

15. Quinton, M.-C.; Bodeau, S.; Kontar, L.; Zerbib, Y.; Maizel, J.; Slama, M.; Masmoudi, K.; Lemaire-Hurtel, A.-S.; Bennis, Y. Neurotoxic Concentration of Piperacillin during Continuous Infusion in Critically Ill Patients. Antimicrob. Agents Chemother. 2017, 61, e00654-17. [CrossRef] [PubMed]

16. Imani, S.; Buscher, H.; Marriott, D.; Gentili, S.; Sandaradura, I. Too much of a good thing: A retrospective study of $\beta$-lactam concentration-toxicity relationships. J. Antimicrob. Chemother. 2017, 72, 2891-2897. [CrossRef]

17. Lodise, T.P.; Lomaestro, B.; Drusano, G.L. Piperacillin-tazobactam for Pseudomonas aeruginosa infection: Clinical implications of an extended-infusion dosing strategy. Clin. Infect. Dis. 2007, 44, 357-363. [CrossRef]

18. Craig, W.A. State-of-the-Art Clinical Article: Pharmacokinetic/Pharmacodynamic Parameters: Rationale for Antibacterial Dosing of Mice and Men. Clin. Infect. Dis. 1998, 26, 1-10. [CrossRef]

19. Felton, T.W.; Hope, W.W.; Lomaestro, B.M.; Butterfield, J.M.; Kwa, A.L.; Drusano, G.L.; Lodise, T.P. Population pharmacokinetics of extended-infusion piperacillin-tazobactam in hospitalized patients with nosocomial infections. Antimicrob. Agents Chemother. 2012, 56, 4087-4094. [CrossRef]

20. Langgartner, J.; Lehn, N.; Glück, T.; Herzig, H.; Kees, F. Comparison of the Pharmacokinetics of Piperacillin and Sulbactam during Intermittent and Continuous Intravenous Infusion. Chemotherapy 2007, 53, 370-377. [CrossRef]

21. Roberts, J.A.; Lipman, J. Optimal Doripenem Dosing Simulations in Critically Ill Nosocomial Pneumonia Patients With Obesity, Augmented Renal Clearance, and Decreased Bacterial Susceptibility. Crit. Care Med. 2013, 41, 489-495. [CrossRef] [PubMed]

22. Lau, W.K.; Mercer, D.; Itani, K.M.; Nicolau, D.P.; Kuti, J.L.; Mansfield, D.; Dana, A. Randomized, Open-Label, Comparative Study of Piperacillin-Tazobactam Administered by Continuous Infusion versus Intermittent Infusion for Treatment of Hospitalized Patients with Complicated Intra-Abdominal Infection. Antimicrob. Agents Chemother. 2006, 50, 3556-3561. [CrossRef]

23. Dulhunty, J.M.; Roberts, J.A.; Davis, J.S.; Webb, S.A.R.; Bellomo, R.; Gomersall, C.; Shirwadkar, C.; Eastwood, G.M.; Myburgh, J.; Paterson, D.L.; et al. Continuous infusion of beta-lactam antibiotics in severe sepsis: A multicenter double-blind, randomized controlled trial. Clin. Infect. Dis. 2013, 56, 236-244. [CrossRef]

24. Abdul-Aziz, M.H.; Lipman, J.; Akova, M.; Bassetti, M.; De Waele, J.J.; Dimopoulos, G.; Dulhunty, J.; Kaukonen, K.-M.; Koulenti, D.; Martin, C.; et al. Is prolonged infusion of piperacillin/tazobactam and meropenem in critically ill patients associated with improved pharmacokinetic/pharmacodynamic and patient outcomes? An observation from the Defining Antibiotic Levels in Intensive care unit patients (DALI) cohort. J. Antimicrob. Chemother. 2016, 71, 196-207. [PubMed]

25. Abdul-Aziz, M.H.; Sulaiman, H.; Mat-Nor, M.-B.; Rai, V.; Wong, K.K.; Hasan, M.S.; Abd Rahman, A.N.; Jamal, J.A.; Wallis, S.C.; Lipman, J.; et al. Beta-Lactam Infusion in Severe Sepsis (BLISS): A prospective, two-centre, open-labelled randomised controlled trial of continuous versus intermittent beta-lactam infusion in critically ill patients with severe sepsis. Intensive Care Med. 2016, 42, 1535-1545. [CrossRef] [PubMed]

26. Rhodes, N.J.; MacVane, S.H.; Kuti, J.L.; Scheetz, M.H. Impact of loading doses on the time to adequate predicted beta-lactam concentrations in prolonged and continuous infusion dosing schemes. Clin. Infect. Dis. 2014, 59, 905-907. [CrossRef] [PubMed]

27. Wong, G.; Brinkman, A.; Benefield, R.J.; Carlier, M.; De Waele, J.J.; El Helali, N.; Frey, O.; Harbarth, S.; Huttner, A.; McWhinney, B.; et al. An international, multicentre survey of $\beta$-lactam antibiotic therapeutic drug monitoring practice in intensive care units. J. Antimicrob. Chemother. 2014, 69, 1416-1423. [CrossRef]

28. Cockcroft, D.W.; Gault, M.H. Prediction of creatinine clearance from serum creatinine. Nephron 1976, 16, 31-41. [CrossRef]

29. Levey, A.S.; Stevens, L.A.; Schmid, C.H.; Zhang, Y.L.; Castro, A.F.; Feldman, H.I.; Kusek, J.W.; Eggers, P.; Van Lente, F.; Greene, T.; et al. A new equation to estimate glomerular filtration rate. Ann. Intern. Med. 2009, 150, 604-612. [CrossRef]

30. Kidney Disease: Improving Global Outcomes (KDIGO) Acute Kidney Injury Work Group. KDIGO Clinical Practice Guideline for Acute Kidney Injury. Kidney Int. Suppl. 2012, 2, 1-138. 
31. The European Committee on Antimicrobial Susceptibility Testing. Breakpoint Tables for Interpretation of MICs and Zone Diameters. Version 11. 2021. Available online: http:/ / www.eucast.org (accessed on 24 March 2021).

32. Spanish Agency of Medicines and Medical Devices (AEMPS). Piperacilina/Tazobactam SPC, Ficha técnica Piperacilina/Tazobactam Sandoz 4, g./.0.; $5 \mathrm{~g}$ polvo para solución para perfusión, E.F.G. Agencia Española Del Medicamento y Productos Sanitarios (AEMPS). Available online: https:/ / cima.aemps.es/cima/dochtml/ft/71286/FT_71286.html (accessed on 24 March 2021).

33. McWhinney, B.C.; Wallis, S.C.; Hillister, T.; Roberts, J.A.; Lipman, J.; Ungerer, J.P.J. Analysis of 12 beta-lactam antibiotics in human plasma by HPLC with ultraviolet detection. J. Chromatogr. B. Analyt. Technol. Biomed. Life Sci. 2010, 878, 2039-2043. [CrossRef]

34. U.S. Department of Health and Human Service s Food and Drug Administration Center for Drug Evaluation and Research (CDER) Center for Veterinary Medicine (CVM). Guidance for Industry, Bioanalytical Method Validation. 2018. Available online: https: / / www.fda.gov/files/drugs/published/Bioanalytical-Method-Validation-Guidance-for-Industry.pdf (accessed on 24 March 2021).

35. Neely, M.N.; van Guilder, M.G.; Yamada, W.M.; Schumitzky, A.; Jelliffe, R.W. Accurate Detection of Outliers and Subpopulations with Pmetrics, a Nonparametric and Parametric Pharmacometric Modeling and Simulation Package for R. Ther. Drug Monit. 2012, 34, 467-476. [CrossRef]

36. Goutelle, S.; Bourguignon, L.; Maire, P.H.; Van Guilder, M.; Conte, J.E.; Jelliffe, R.W. Population Modeling and Monte Carlo Simulation Study of the Pharmacokinetics and Antituberculosis Pharmacodynamics of Rifampin in Lungs. Antimicrob. Agents Chemother. 2009, 53, 2974-2981. [CrossRef]

37. Roberts, J.A.; Paul, S.K.; Akova, M.; Bassetti, M.; De Waele, J.J.; Dimopoulos, G.; Kaukonen, K.-M.; Koulenti, D.; Martin, C.; Montravers, P.; et al. DALI: Defining antibiotic levels in intensive care unit patients: Are current $\beta$-lactam antibiotic doses sufficient for critically ill patients? Clin. Infect. Dis. 2014, 58, 1072-1083. [CrossRef] [PubMed]

38. Wong, G.; Briscoe, S.; Adnan, S.; McWhinney, B.; Ungerer, J.; Lipman, J.; Roberts, J.A. Protein binding of $\beta$-lactam antibiotics in critically ill patients: Can we successfully predict unbound concentrations? Antimicrob. Agents Chemother. 2013, 57, 6165-6170. [CrossRef] [PubMed]

39. Kang, C.-I.; Kim, S.-H.; Park, W.B.; Lee, K.-D.; Kim, H.-B.; Kim, E.-C.; Oh, M.-D.; Choe, K.-W. Bloodstream infections caused by antibiotic-resistant gram-negative bacilli: Risk factors for mortality and impact of inappropriate initial antimicrobial therapy on outcome. Antimicrob. Agents Chemother. 2005, 49, 760-766. [CrossRef]

40. Peralta, G.; Lamelo, M.; Álvarez-García, P.; Velasco, M.; Delgado, A.; Horcajada, J.P.; Montero, M.; Roiz, M.P.; Fariñas, M.C.; Alonso, J.; et al. Impact of empirical treatment in extended-spectrum beta-lactamase-producing Escherichia coli and Klebsiella spp. bacteremia. A multicentric cohort study. BMC Infect. Dis. 2012, 12, 245. [CrossRef] [PubMed] 